Kimberley McLaughlin, Polly Traxler, Wendy Valentine. The Hospice of St Francis, Berkhamsted, UK

\subsection{6/bmjspcare-2013-000591.115}

Context "Hospices will need to change is beyond doubt. The scale of the challenge ahead is dramatic and will require hospices to significantly increase the extent and scope of end of life services" (Calanzani et al 2013). Since 2007, cancer diagnoses have increased by $16 \%$ in Hertfordshire and over the next 10 years projected to rise a further $14 \%$. This collaborative project with our neighbouring hospice provides a locality-wide community programme to support those recently diagnosed or living with serious illness, their families, carers, friends and the community. Over the next 3 years, The Spring Centre will reach over 1,000 more patients and their families.

Approach Re-aligning existing resources and community engagement is key to our programme. The St Francis Choir, Coffee Mornings and Film Club engage our community in regular activities throughout the year. Medical, nursing and therapists clinics provide physical, emotional and psychological support. Focused groups by our rehabilitation team range from fatigue management workshops, breathlessness groups, complementary therapy, gardening and creative therapies. Our Carers programme offers individualised support including benefits advice and relaxation classes. A variety of groups for bereaved adults, children and young people invite opportunities to share experiences, enjoy our gardens and even cooking classes! Outcome measures used to identify the effectiveness of attending the pilot fatigue group in 2012 showed that $80 \%$ of people felt they had the skills and energy levels to participate in more social or work activities. Feedback also highlights benefits, 'the carers' support group is a lifeline to me'.

Conclusion The Spring Centre at The Hospice of St Francis is an example of thinking strategically and collaboratively about the role of our hospice, re-aligning existing resources and delivering the care that people want and need.

\section{P94 DEVELOPING A MOTOR NEURONE DISEASE (MND) SERVICE IN AUSTERE TIMES: THE POWER OF PARTNERSHIP WORKING}

Karen Coupland. Sue Ryder, Moggerhanger, UK

\subsection{6/bmjspcare-2013-000591.116}

Background Prior to the changes, pockets of good practice existed but services were uncoordinated and communication ineffective. Care was often reactive in response to crises and patients reported feeling unsupported and uncertain whom to contact should their condition change. A multi-disciplinary MND clinic existed; however this was hospital based, difficult to access and community service provision was patchy. The need to improve services was identified at a stakeholder event, which brought more than 60 people with MND, carers, professionals and commissioners together.

The post of MND Coordinator was developed in discussion with the local MND Association, and supported by the local NHS Primary Care Trust. The post was funded and based within our local hospice in Bedfordshire, with the aim to take the lead and establish a single point of contact from diagnosis to death, for people with MND.

Clinical outcomes
- Timely referrals to agencies for equipment, adaptations, therapy, information and support

- MDT clinic moved, making this more accessible, as well as promoting sensitive introduction of hospice and palliative care services - improving access and advanced care planning

- Domiciliary visits offered for support, monitoring and hospital avoidance

- Discharge planning from hospital/hospice to reduce length of stay

- Local organisations working together, promotes psychological and emotional wellbeing for people with MND and their carers and encourages selfmanagement

- Health and social care professionals benefited from MND specific education delivered collaboratively by statutory and charitable services

Comments received 'The clinic is in such a lovely setting and much better for patients to attend than hospital'

'It is a hugely important role. Having someone there to monitor the health and wellbeing of people, who otherwise can fall down a hole.'

Recommendations Identify opportunities for collaborative working with local champions, using the voice of people living with MND and their carers to identify poor quality services and drive up standards.

\section{P95 ABOVE AND BEYOND - THE POWER OF INTERNATIONAL PARTNERSHIPS}

${ }^{1}$ Kate North, ${ }^{2}$ Joan Marston, ${ }^{3}$ Lameck Thambo, ${ }^{3}$ Jean Tauzie, ${ }^{4}$ Anil Paleri, ${ }^{4}$ Pradnya Talawadeka, ${ }^{5}$ Maryann Muckaden, ${ }^{6}$ Fred Chipulta. ${ }^{1}$ Help the Hospices, London, UK, ${ }^{2}$ International Children's Palliative Care Network, ${ }^{3}$ Palliative Care Association of Malawi, ${ }^{4}$ Indian Association of Palliative Care, ${ }^{5}$ Tata Memorial Hospital, Mumbai, ${ }^{6}$ Umodzi Clinic, Malawi

\subsection{6/bmjspcare-2013-000591.117}

Introduction This project brings together partners from India, South Africa, Malawi and the UK to expand children's palliative care services in Maharashtra state in India and in Malawi.

The project results have prompted commitment to palliative care service development above and beyond the original project scope. It demonstrates how international partnerships can inspire and promote others to take on palliative care to meet the huge need for palliative care around the world.

Methods The project uses international donor funds to integrate children's palliative care into existing services in both urban and rural settings.

Each partner brings to the project distinct skills and experience; ranging from project and donor management, paediatric palliative care knowledge, training and mentorship expertise, and advocacy skills.

Results The mix of these skills has seen the following key results:

- The development of children's palliative care services in 5 new settings.

- The integration of children's palliative care into health service curricula.

- The inclusion of children's palliative care in draft palliative care policy.

The project has also prompted extended impact:

- The National Rural Health Mission (Jawhar, India) has committed to a wider programme of palliative care 